and Large White) and of the Mongrel breed were inventoried and characterized according to the data from the literature. The local breed (61\% of pig number) is more present in the breeding zone, followed by the Korhogo breed (34\%), the Mongrel race (4\%) and Large White $(0.48 \%)$. According to the breeding systems, the Korhogo breed is exclusively reared in the intensive system, the Korhogo breed followed by the local breed in the semi intensive and the local breed followed by the Korhogo breed in the traditional system. The Korogho breed was the more implicated in the exchanges of boars in the various systems than the other breeds (local breeds and mongrel). Pig meat transformers and distributors in Bobo-Dioulasso globally prefer the local breed (51.41\%) more than improved breeds (40\%). Butchers and Pork butchers prefer the local breed $(50 \%)$ as well as improved breeds (50\%), (Korhogo breed, Large White breed and Mongrel breed). Cookers with a furnace prefer the local breed (53.33\%) more than improved breeds (40). Restorer (1/1) and a part of Cookers with the furnace $(6.67 \%)$ do not choose a breed. In conclusion, the presence and importance of the local breed or improved breed are characteristic of pig breeding systems. The uncontrolled exchanges and hazardous crossing between pig breeds constitute risks of absorption of the local breed, consanguinity and threat on genetic diversity. It is necessary to carry out a genotypic characterization of these breeds in order to better organize a more productive and durable management of pig breeds and breeding in the zone of Bobo-Dioulasso.

\title{
Is there room for selection in a small local pig breed? - a simulation study
}

\author{
Jean-Luc Gourdine ${ }^{1 \dagger}$, A. C. Sørensen ${ }^{2}$ and L. Rydhmer ${ }^{3}$ \\ ${ }^{1}$ Institut National de la Recherche Agronomique, UR143, Unité de Recherches Zootechniques, 97170 Petit Bourg, Guadeloupe, France, ${ }^{2}$ University of Aarhus, Faculty \\ of Agricultural Sciences, Department of Genetics and Biotechnology, P.O. Box 50, DK-8830 Tjele, Denmark; ${ }^{3}$ Animal Sciences Group of Wageningen UR, PO Box 65, \\ 8200 AB Lelystad The Netherlands; Swedish University of Agricultural Sciences, Department of Animal Breeding and Genetics, PO Box 7023, SE-75007 Uppsala, Sweden
}

\section{Introduction}

Local breeds are defined as breeds that occur only in one country (FAO, 2007). It is important that the pig biodiversity be maintained by keeping and using a sufficient numbers of breeds, in order to secure the availability of important genes for future needs (Fimland, 2007). Furthermore, "loss of local breeds will cause cultural erosion and diminish the ability of communities to maintain their cultures and livelihoods" (FAO, 2007). There are few examples of well defined breeding programs with selection for genetic improvement of local pig breeds. Focus is on management of genetic diversity in small populations. However, in the presence of pedigree information, optimal contribution selection (OCS) can be applied to control inbreeding rate and simultaneously avoid low performance in valuable traits (Meuwissen, 1997). Strategies for moving from conservation to utilisation include defining the breeding goal and marketing the products to secure profitability (Gandini and Oldenbroek, 2007). If the products are marketed as "high quality", it could be wise to select for the weakest meat quality trait of the breed. The main objective of the present paper was to examine, using stochastic simulation (Pedersen et al., 2009), the possibility to design a breeding program to improve a key trait in a small local breed population without increasing inbreeding above the recommended rate.

\section{Materials and Methods}

A pig population with the characteristics of a small local breed population in an extensive system was simulated. The population consisted of 860 male and female reproducers in 35 herds or 2002 male and female reproducers in 77 herds. The production system was a commercial production of high quality products for a niche market. Each sow weaned 3 female and 3 male piglets and produced 2 litters per year with a maximum of 6 litters. Of the male piglets, 2 were castrated and one was kept intact in each litter. Castration was performed within the first week of birth. Two types of matings were simulated: natural service (NS) and artificial insemination (AI). Litter identity was recorded on the farm at castration and the selection trait was recorded at slaughter. The breeding goal consisted of one meat quality trait (MQT), recorded at the slaughterhouse on relatives of selected boar and gilt candidates. A breeding scheme with optimal contribution selection (OCS) was compared to a breeding scheme with BLUP selection (BLUP) and to a scheme with no selection (NoS). OCS was performed using EBV based on information from relatives (BLUP-EBV selection). Thus, selection was based on information from relatives. The infinitesimal model was used to estimate BLUP EBV, with the fixed effect of herd year season and the random additive genetic effect, the random maternal environmental effect and the residual. The additive genetic variance was set to 1 , so that the estimated genetic change is directly expressed in genetic standard deviations. This study used the stochastic simulation program ADAM (Pedersen et al., 2009) to calculate the genetic progress and the rate of inbreeding per generation in each breeding scheme. Simulations were performed by applying ADAM to 20 scenarios, different with regards to number of herds (35 vs. 77); type of mating (AI vs. NS); selection rules (NoS, BLUP or OCS) and heritability of MQT $\left(\mathrm{h}^{2}=0.2\right.$ vs. 0.4). All scenarios were replicated 50 times. Statistical tests of differences between scenarios in rates of genetic gain and inbreeding were performed (proc GLM, SAS ${ }^{\odot}$ ), with the fixed effects of time.

\footnotetext{
† E-mail: Jean-Luc.Gourdine@antilles.inra.fr
} 


\title{
Results
}

The generation interval, ranging from 1.49 (OCS) to 1.83 (BLUP), did not differ significantly between the 20 different scenarios. The average accuracy was 0.51 . The genetic gain increased from NoS to BLUP with slightly lower values for OCS than for BLUP. The difference between OCS and BLUP in genetic progress was not significant. Type of mating did not affect rate of inbreeding or genetic gain. The value of heritability of MQT did not affect the genetic gain, but the genetic gain tended to be higher with $h^{2}$ of 0.4 than 0.2 . The rate of inbreeding was significantly lower $(P<0.05)$ in NoS and OCS than in BLUP. The rate of inbreeding in BLUP schemes was significantly affected by the population size $(P<0.05)$, with lower values in the population of 2002 animals than in the population of 860 animals. The first 4 years in the simulation corresponded to the time to build the structure and to have some information to evaluate the genetic progress. Whatever the population size, there is no genetic gain in NoS schemes. Genetic gain in BLUP schemes was slightly higher than in OCS schemes $(P<0.05)$. Inbreeding coefficients fluctuate in BLUP schemes with substantial rise in the last 5 years, especially in the smaller population. In NoS and OCS schemes, inbreeding coefficients remained constant along the years with higher values in OCS schemes than in NoS schemes. The simulations showed that in the smallest population (860 animals in the nucleus), inbreeding increased by $0.7 \%$ when mating was performed at random. In the system with 77 herds (2002 reproducers), inbreeding was the highest with the BLUP scenario (3.2\%) whereas low values were obtained in OCS and NoS scenarios (0.85 and $0.42 \%$, respectively). With OCS, a genetic progress almost as large as with truncation can be achieved (0.32-0.47 vs. $0.40-0.50$ genetic sd) at a considerably lower rate of inbreeding (0.7-1.2 vs. $2.3-5.1 \%)$.

\section{A scheme for improvement of smallholder goat production in Indian villages}

\author{
Chanda Nimbkar ${ }^{\dagger}$, K. P. Unaune, K. M. Chavan and P. M. Ghalsasi
}

Nimbkar Agricultural Research Institute, P.O. Box 23, 415523, Phaltan, Maharashtra, India

The Indian Council of Agricultural Research has implemented the All India Coordinated Research Project (AICRP) on Goat Improvement which has been going on for more than ten years. Currently there are 12 field units for different breeds in different parts of the country and three organizational farm units. The objectives of the field units are to assess the production performance of goat breeds in village flocks and improve them through selection, to evaluate the economics of goat production and to disseminate pro-poor goat based technologies and evaluate their impact on goat production. A field unit for the Osmanabadi goat breed was started at the Nimbkar Agricultural Research Institute (NARI) in April 2009 under this project. It is aimed to use the information collected under this field unit to promote comprehensive goat development including genetic improvement in the areas covered by the field unit.

Under the Osmanabadi goat field unit, a survey of the socio-economic status and goat management practices of goat keepers of Bibi and Wadgaon villages, $20 \mathrm{~km}$ from Phaltan town, in the Satara District of Maharashtra State of India was carried out in September-0ctober 2009 with a specially designed questionnaire. There were 469 households in total in Bibi and 138 in Wadgaon according to the 2001 census. Out of these, 55 households in Bibi and 37 in Wadgaon reared goats. All the 92 goat owners/keepers owning 337 adult does (and 194 kids) were interviewed in the two villages. Phenotypic characteristics and body weights of their goats were recorded after individual identification of all adult does with ear tags. NARI's extension workers visit all the goat owners periodically and record births, deaths and sales, body weight of kids and does, milk yield of does, expenditure incurred on goat rearing and income earned. A database using MS Access has been specially prepared to store and retrieve the data for analysis. The extension workers organize vaccination, deworming and spraying of villagers' goats against ecto-parasites. Training leaflets in the local Marathi language are being prepared to create awareness among goat keepers about vaccination and first-aid treatment.

Fifty-one percent of the 92 goat keepers owned only one adult doe each; another $29 \%$ had 2-3 does; 7\% had 4-6; 7\% had 7-10 does, 5\% had 11-16 does and only two owners had more than 20 adult does each (one of these had 46 adult does). The majority of goat owners (80\%) thus had less than 3 adult does each. However, they owned only $34 \%$ of the total number of goats. Forty-seven percent of the goats were owned by those having 10 or more does each. The existence of a large number of goat owners having only one or two does poses a challenge to implementing development strategies since most of these owners understandably do not appear to have the high level of interest and involvement in improving their goats as the larger goat owners. Thirty-eight percent of the goat owners from Bibi and $35 \%$ of those from Wadgaon also owned cows and buffaloes. Those that owned more than 10 does tended not to own any cows or buffaloes.

Seventy percent of the goat keepers did not give any supplementary feeding to their goats and relied almost entirely on available natural grazing and browsing from neem and acacia trees for the sustenance of their goats. They grazed goats on either their own land or on common lands. The 30\% who provided some supplementary feeding, gave about $100 \mathrm{~g}$ homegrown grain (i.e. wheat, sorghum, pearl millet or maize) to kids and kidded does for 3-4 months after kidding. Only four goat owners purchased expensive high protein feed such as groundnut cake mainly for kids. The average expenditure on feeding per kidded doe and its kids was Rs.189.

\footnotetext{
${ }^{\dagger}$ E-mail: chanda.nimbkar@gmail.com
} 